\title{
Haemato-Protective and Hypolipidemic Effects of Aqueous Extract of Libyan Propolis Against Sodium Nitrite Induced Haematotoxicity and Hyperlipidemia in Guinea Pigs
}

\author{
Azab Elsayed Azab ${ }^{1}$, Nuri Mohamed Lashkham ${ }^{2}$, Mohamed Omar Albasha ${ }^{1}$ \\ ${ }^{1}$ Department of Zoology, Faculty of Science, Zawia University, Alejelat, Libya \\ ${ }^{2}$ Faculty of Medical Technology, Zawia University, Surman, Libya
}

Email address:

azabelsaied@yahoo.com (A. E. Azab)

To cite this article:

Azab Elsayed Azab, Nuri Mohamed Lashkham, Mohamed Omar Albasha. Haemato-Protective and Hypolipidemic Effects of Aqueous Extract of Libyan Propolis Against Sodium Nitrite Induced Haematotoxicity and Hyperlipidemia in Guinea Pigs. American Journal of Bioscience and Bioengineering. Vol. 3, No. 4, 2015, pp. 22-32. doi: 10.11648/j.bio.20150304.11

\begin{abstract}
Flavonoids and various phenolics are the most important pharmacologically active constituents in propolis capable of scavenging free radicals. The present work aimed to evaluate the effectiveness of aqueous extract of Libyan propolis as a natural source of antioxidants to minimize the harmful effects of sodium nitrite induced haematotoxicity and hyperlipidemia in Guinea pigs. In this study, Twenty four adult male Guinea pigs were used for this study and divided into four groups. The first group was control group, the $2^{\text {nd }}$ was the propolis group orally received propolis $(200 \mathrm{mg} / \mathrm{kg}$ body wt $)$, the $3^{\text {rd }}$ was the experimental and received sodium nitrite orally at a dose of $80 \mathrm{mg} / \mathrm{kg}$ body weight, the $4^{\text {th }}$ one co-administered sodium nitrite orally at a dose of $80 \mathrm{mg} / \mathrm{kg}$ body weight with propolis ( $200 \mathrm{mg} / \mathrm{kg}$ body wt) daily for 35 days. Blood samples were obtained for assessment of haematological parameters and serum lipids profile. In sodium nitrite treated animals, there were severe haematological changes and dyslipidemia. Haematologically, Guinea pigs that received sodium nitrite orally at a dose of 80 $\mathrm{mg} / \mathrm{kg}$ body weight daily for 35 days had significantly $(\mathrm{p}<0.05)$ lower red blood cell count, hemoglobin content, haematocrit, mean corpuscular volume, mean corpuscular hemoglobin, mean corpuscular hemoglobin concentration, white blood cell count, and platelets count than those in the control animals. On the other hand, mean corpuscular volume of sodium nitrite treated animals was significantly $(\mathrm{p}<0.05)$ elevated as compared to the control animals. The serum cholesterol, triglycerides, low density lipids cholesterol, very low density lipids cholesterol concentrations, and the atherogenic ratios based on lipid profile parameters (Castelli's risk index I, Castelli's risk index II, atherogenic coefficient and atherogenic index of plasma) were increased and serum high density lipids cholesterol concentration was decreased in sodium nitrite treated group. Co-administration of propolis significantly improved of all haematological and lipid profile parameters, and atherogenic ratios parameters. It can be concluded that, sodium nitrite had adverse effects on haematological, lipid profile parameters, and the atherogenic ratios parameters. Propolis supplementation showed a remarkable amelioration of these abnormalities in sodium nitrite treated male Guinea pigs. It is recommended that the use of sodium nitrite must be limited and use of propolis as antioxidant to prevent the toxic effect. Further studies are necessary to elucidate exact mechanism of protection of haematotoxicity, hyperlipidemia, atherogenic and potential usefulness of aqueous extract of Libyan propolis as a protective agent against sodium nitrite induced haematotoxicity, dyslipidemia and atherogenic in clinical trials.
\end{abstract}

Keywords: Haemato-Protective, Hypolipidemic, Anti-atherogenic, Libyan Propolis, Male Guinea Pig, Sodium Nitrite

\section{Introduction}

Nitrite salts are added to meats, poultry, and fish in minute quantities as a means of preservation; this has been a common practice for many centuries [1]. Nitrite in meat greatly delays the development of botulinum toxin, develops cured meat flavor and color, retards the development of rancidity during storage, inhibits the development of warmed-over flavor and preserves the flavors of spice and smoke [2].

The addition of $\mathrm{NaNO}_{2}$ as a food additive, to our foods may react with amines of the foods in the stomach and produces nitrosamines or large numbers of free radicals. Such products may increase lipid peroxidation which can create many 
harmful hazards to the different body organs [3]. Sodium nitrite has been reported to have adverse health effects due to increased oxidative stress that could be harmful to different organs [1]. The reactive nitrogen species that are produced by exposure to nitrite have many toxic effects including hepatotoxicity, nephrotoxicity and dysregulation of inflammatory responses, tissue injury [4], haematotoxicity [5, 6], and hyperlipidemic effects [1, 7].

Natural antioxidants strengthen the endogenous antioxidants defenses from reactive oxygen species and restore the optimal balance by neutralizing the reactive species [8]. The antioxidant activities of phenolics are related to a number of different mechanisms, such as free radical-scavenging, hydrogen-donation, singlet oxygen quenching, metal ion chelation, and acting as a substrate for radicals such as superoxide and hydroxyl [9]. Propolis is a wax-like resin produced by honeybees from substances collected from plants, which are mixed with beeswax and other compounds of bee metabolism. It's a mixture of balsams and resins, waxes, essential oils, pollen, and other substances which is used by bees in the construction, repair and protection of their hives, mainly due to its mechanical properties and antimicrobial activity [10].

Recently, propolis has been used for upper respiratory tract infections, common cold, flu-like infections, as dermatological preparations in wound healing, treatment of burns, acne, herpes simplex and genitalis, and neurodermatitis, as mouthwashes and toothpastes to prevent caries and treat gingivitis and stomatitis; in cosmetics; and in health foods and beverages not only to improve health and prevent diseases, but also as an ingredient in many dietary supplements and nutraceuticals $[10,11]$.

Propolis possesses several biological properties, such as antioxidant [12], immuno-stimulating [13], haemtoprotective [14] hepato-protective [15], hypolipidemic and antiatherogenic [16]. Melatonin and caffeic acid phenethyl ester are compounds of honey bee propolis that were recently found to be potent free radical scavengers and antioxidants. Many flavonoids are known to be antioxidants, and several of these, such as quercetin which has been identified as constituents of propolis have been shown to be inhibitors of low density lipoprotein oxidation [17]. The evidence reporting the amelioration by aqueous extract of propolis in sodium nitrite induced haematotoxicity, hyperlipidemia, atherogenic effects in Guinea pigs are hardly found. So, the present work aimed to evaluate ameliorating effect by aqueous extract of Libyan propolis in sodium nitrite induced haematotoxicity, hyperlipidemia, atherogenic effects in guinea pigs.

\section{Materials and Methods}

\subsection{Chemicals}

Sodium nitrite $\left(\mathrm{NaNo}_{2}\right)$ was purchased from Sigma Aldrich, St Louis, MO. It was applied as a freshly prepared solution and given by gavages at a dose of $80 \mathrm{mg} / \mathrm{kg}$ body weight as previously described [ $1 \& 18$ ], daily for 35 days.
Propolis samples were collected from different localities of Surman city, west Libya. Aqueous propolis extract was prepared according to the method of El-khayat et al. [19]. Briefly, propolis was kept dry and freezed $\left(-40^{\circ} \mathrm{C}\right)$ until used. Propolis samples were mixed with distilled water, heated gently and filtered through Whatman No. 1 filter paper. The choice of the dose of propolis was based on the results of the previous studies, where the antioxidant effect of this agent was confirmed. Propolis was freshly prepared and administered to animals orally by gavage at a dose of $200 \mathrm{mg} / \mathrm{kg}$ body weight [20] once daily for 35 days.

\subsection{Animals}

Twenty four adult male Guinea pigs (Cavia porcellus) weighting 450-600 gm were used for this study. The animals were obtained from animal house unit in the faculty of veterinary medicine, Tripoli University, Libya. The animals were housed in a room under standard conditions of ventilation, temperature $\left(25 \pm 2{ }^{\circ} \mathrm{C}\right)$, humidity $(60-70 \%)$ and light/dark condition (12/12). The animals were provided with tape water ad libitum and fed with the standard commercial chow. The animal procedures were performed in accordance with Guide Lines for Ethical Conduct in the Care and Use of Animals.

\subsection{Experimental Design}

After one week of acclimation, the animals were randomized and divided into four groups (6 Guinea pigs for each) as follow: Group I (Control group): provided with tape water and fed with normal diet.

Group II (Propolis group): The animals received propolis ( $200 \mathrm{mg} / \mathrm{kg}$ body $\mathrm{wt}$ ) orally by gavage daily for 35 days.

Group III (Sodium nitrite treated group): The animals received sodium nitrite orally at a dose of $80 \mathrm{mg} / \mathrm{kg}$ body weight, daily for 35 days.

Group IV (Sodium nitrite/propolis co-administered): The animals received sodium nitrite orally at a dose of $80 \mathrm{mg} / \mathrm{kg}$ body weight followed after two hours by propolis $(200 \mathrm{mg} / \mathrm{kg}$ body wt) orally by gavage daily for 35 days.

At the end of the experimentation and 24 hours after the last dose, all animals were sacrificed under light ether anesthesia, then rapidly dissected and subjected to the following examinations:

\subsection{Blood Sampling}

Blood samples were drawn by cardiac puncture. The first sample was collected in clean dry tube containing the anticoagulant substance EDTA (ethylene diamine tetra acetic acid) and used for the hematological studies. The second sample was collected in clean dry tube and centrifuged at 3000 rpm for 15 minutes then serum was separated and kept in a deep freezer at $-20^{\circ} \mathrm{C}$ until biochemical measurements were carried out.

\subsection{Haematological Parameters}

Red, white blood cells and blood platelets counts were done 
by using the hemocytometer and hemoglobin content $(\mathrm{Hb})$ was determined according to the method of Wong [21]. Hematocrite value (Hct) was estimated by using the heparinized capillary tubes. The mean corpuscular volume (MCV), the mean corpuscular hemoglobin (MCH) and the mean corpuscular hemoglobin concentration (MCHC) were calculated according to Schalm [22] as the following equations: $\mathrm{MCV}=\mathrm{Hct} / \mathrm{RBC}$ 's $\times 10, \mathrm{MCH}=\mathrm{Hb} / \mathrm{RBC}$ 's $\times 10$ $\& \mathrm{MCHC}=\mathrm{Hb} / \mathrm{Hct}) \times 100$.

\subsubsection{Biochemical Analysis}

Total cholesterol concentration was estimated according to Allain et al. [23], triglycerides concentration also by the method of Fossati and Prencipe [24] and HDL cholesterol by Burstein et al., [25]. VLDL-cholesterol and LDL-cholesterol concentrations were estimated by using the Friedewald equation [26]. The atherogenic ratios were calculated as follows: Castelli's risk index (CRI-I) = TC/HDLc, Castelli's risk index $(\mathrm{CRI}-\mathrm{II})=\mathrm{LDLc} / \mathrm{HDLc}$, atherogenic coefficient $(\mathrm{AC})=(\mathrm{TC}-\mathrm{HDLc}) / \mathrm{HDLc}$ and atherogenic index of plasma $(\mathrm{AIP})=\log \mathrm{TG} / \mathrm{HDLc}$.

\subsection{Statistical Analysis}

The values were presented as means \pm SD of different groups. Differences between the mean values were estimated using one way ANOVA. The results were considered statistically significant when $\mathrm{p}<0.05$.

\section{Results}

Haematological parameters in blood of the different groups are shown in Table 1. Guinea pigs that received sodium nitrite orally at a dose of $80 \mathrm{mg} / \mathrm{kg}$ body weight, daily for 35 days had significantly $(\mathrm{p}<0.05)$ lower RBCs count, $\mathrm{Hb}, \mathrm{Ht}, \mathrm{MCH}$, MCHC, WBCs counts, and platelets count, than those in the control animals (Fig. 1 - 3 \& 5 -8). On the other hand, MCV, of sodium nitrite treated Guinea pigs was significantly $(p<0.05)$ elevated as compared to the control Guinea pigs (Fig. 4). Co-administration of sodium nitrite with propolis were significantly $(\mathrm{p}<0.05)$ prevented the changes recorded in blood parameters as compared with control group.

Lipid profile parameters in serum of the different groups are shown in Table 2. Guinea pigs that received sodium nitrite orally at a dose of $80 \mathrm{mg} / \mathrm{kg}$ body weight, daily for 35 days had significantly $(p<0.05)$, increased the serum cholesterol, triglycerides, non HDLc, LDLc and VLDLc concentrations. Co-administration of sodium nitrite with propolis were significantly $(p<0.05)$ prevented the changes recorded in serum cholesterol, triglycerides, non HDLc, LDLc and VLDLc concentrations as compared with control group (Fig. 9, $10 \& 12-14)$. On the other hand, serum HDL cholesterol concentration of sodium nitrite treated Guinea pigs was significantly $(p<0.05)$ decreased as compared to the control animals (Fig. 11). Co-administration of sodium nitrite with propolis was significantly $(\mathrm{p}<0.05)$ prevented the changes recorded in serum HDLc concentration as compared with control group.
Table 3 showed the means and standard deviations for cardiac risk ratio \{Castelli's risk index I (TC/HDLc)\}, Castelli's risk index II (LDLc/HDLc), atherogenic coefficient $\{(\mathrm{TC}-\mathrm{HDLc}) / \mathrm{HDLc}\}$ and Atherogenic Index of Plasma $\{(\mathrm{AIP})=\log (\mathrm{TG} / \mathrm{HDLC})\}$ in control group, propolis group, sodium nitrite treated group and Guinea pigs group co-administrated of sodium nitrite with propolis. These ratios were elevated in sodium nitrite treated Guinea pigs group compared with the control group with statistically significant differences $(p<0.05)$. Co-administration of sodium nitrite with propolis were declined these ratios with statistically significant differences $(\mathrm{p}<0.05)$, when compared with sodium nitrite group (Figs. 13-18).

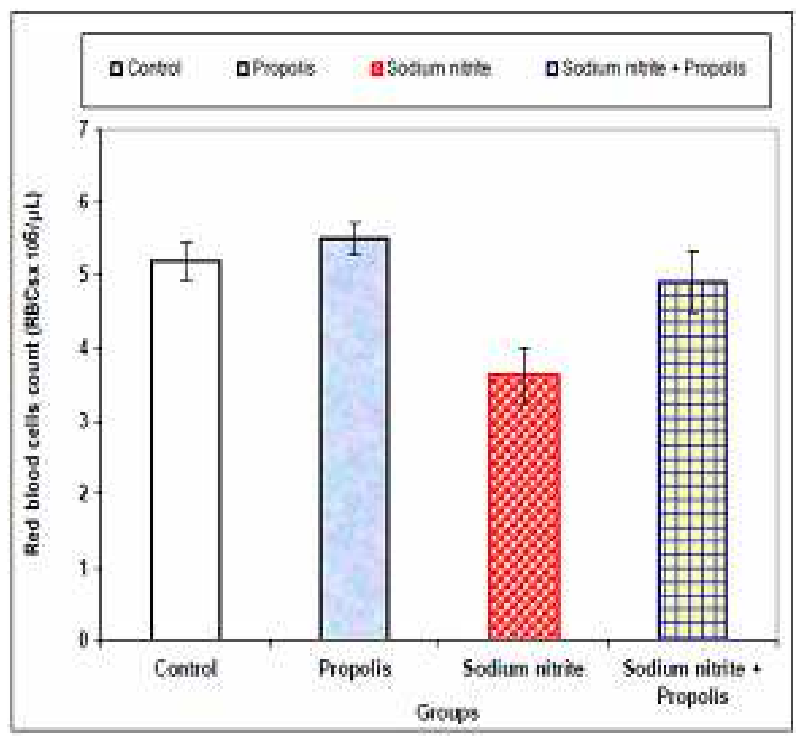

Figure 1. Red blood cells count in different animals groups.



Figure 2. Haemoglobin content in different animals groups. 


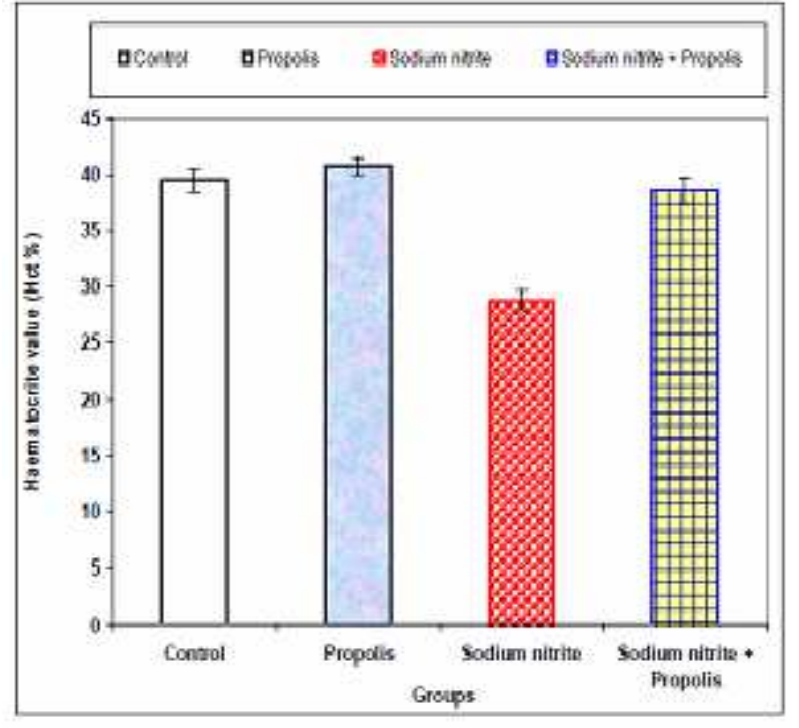

Figure 3. Haematocrite value in different animals groups.



Figure 4. Mean corpuscular volume in different animals groups.

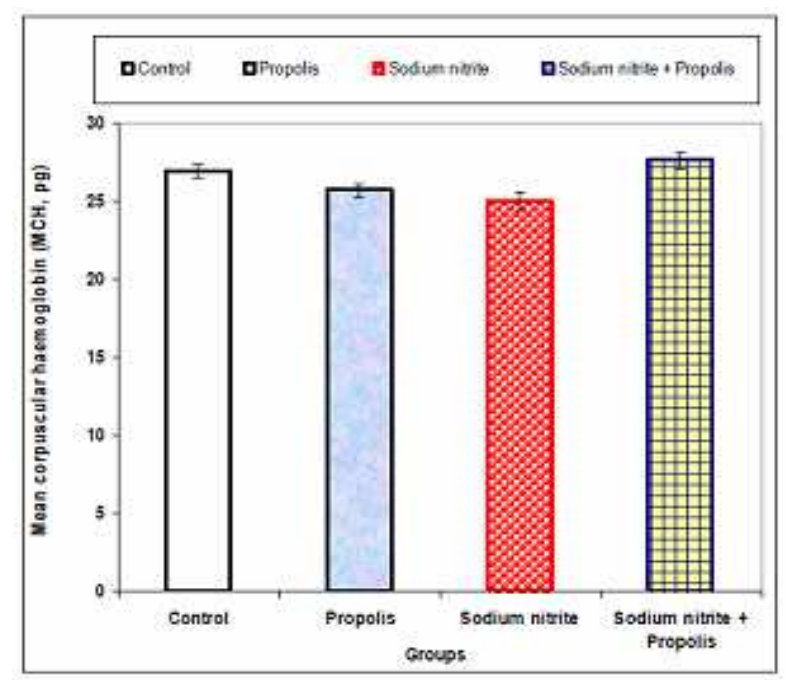

Figure 5. Mean corpuscular haemoglobin in different animals groups.

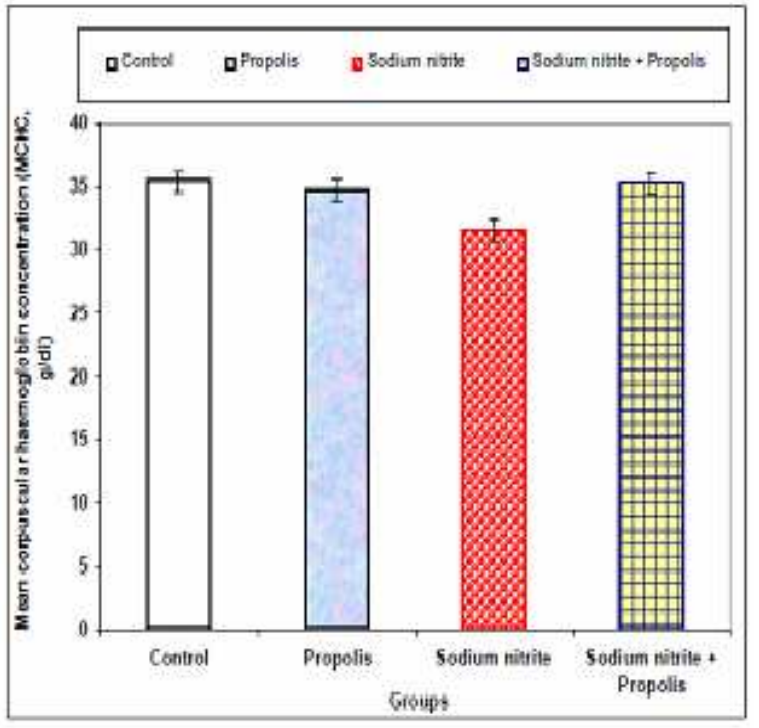

Figure 6. Mean corpuscular haemoglobin concentration in different animals groups.



Figure 7. White blood cells count in different animals groups.

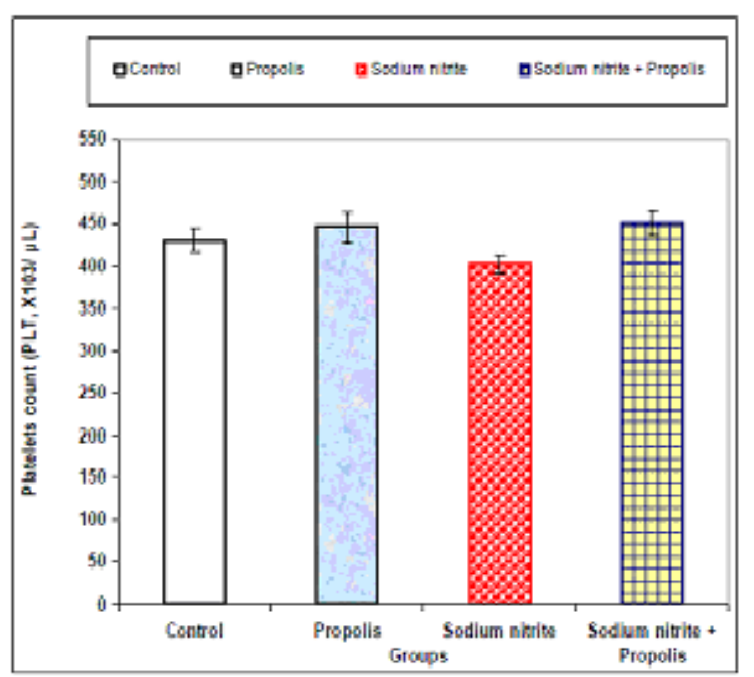

Figure 8. Platelets count in animals different groups. 




Figure 9. Serum cholesterol concentration in different animals groups.

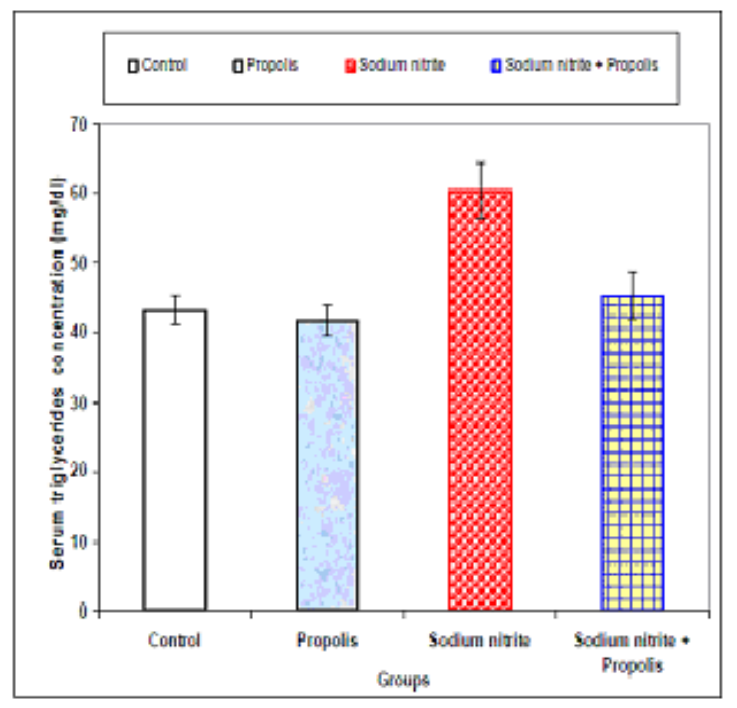

Figure 10. Serum triglycerides concentration in different groups.

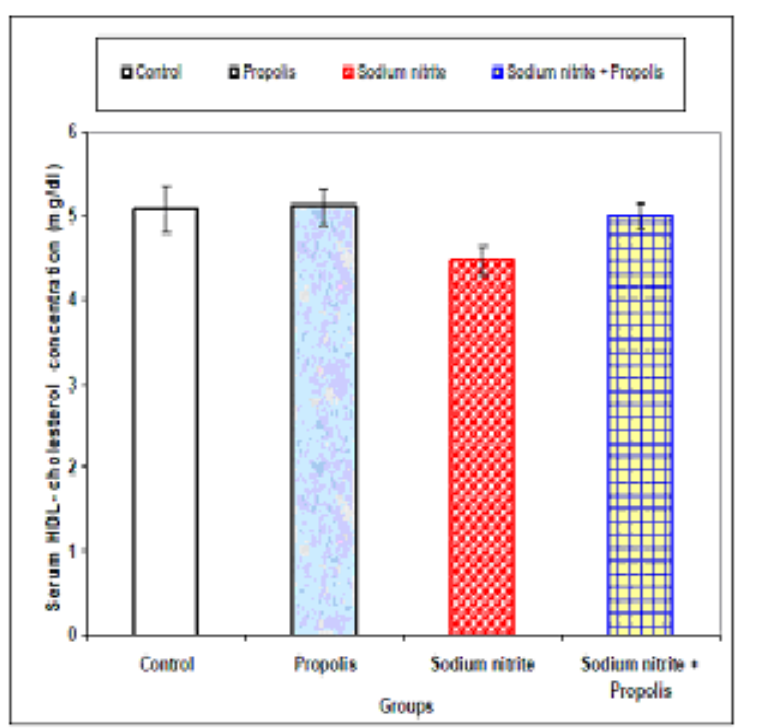

Figure 11. Serum HDL-cholesterol concentration in different animals groups.

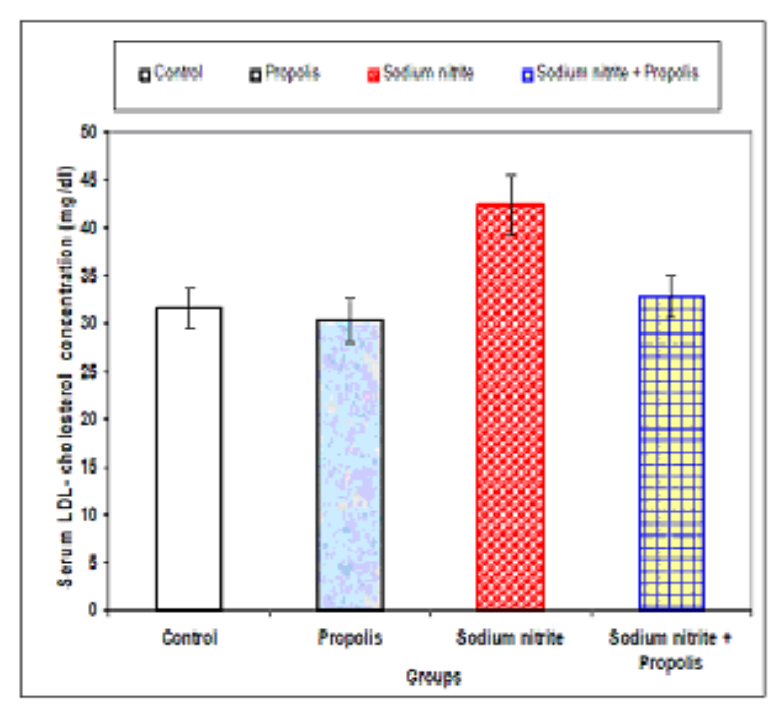

Figure 12. Serum LDL-cholesterol concentration in different groups.

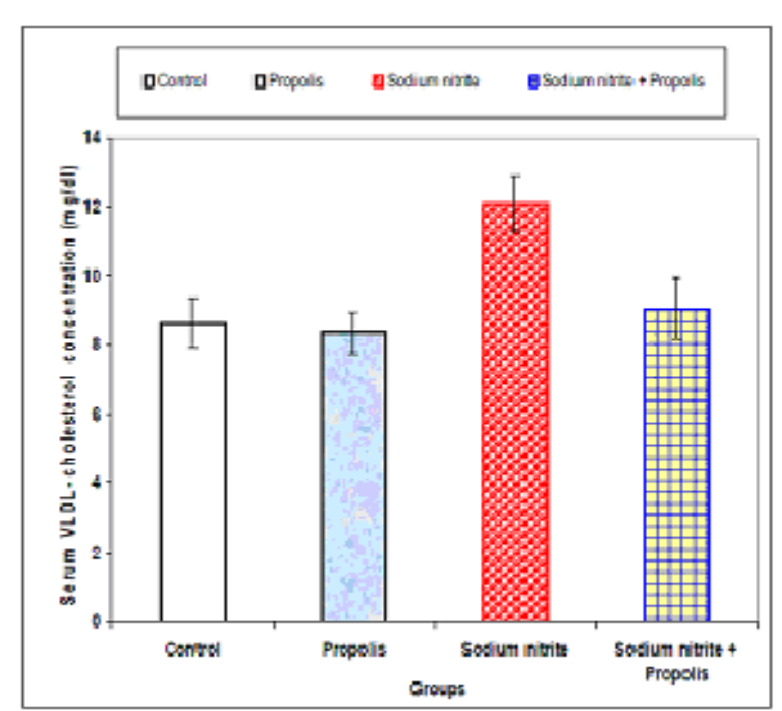

Figure 13. Serum VLDL-cholesterol concentration in different animals groups.

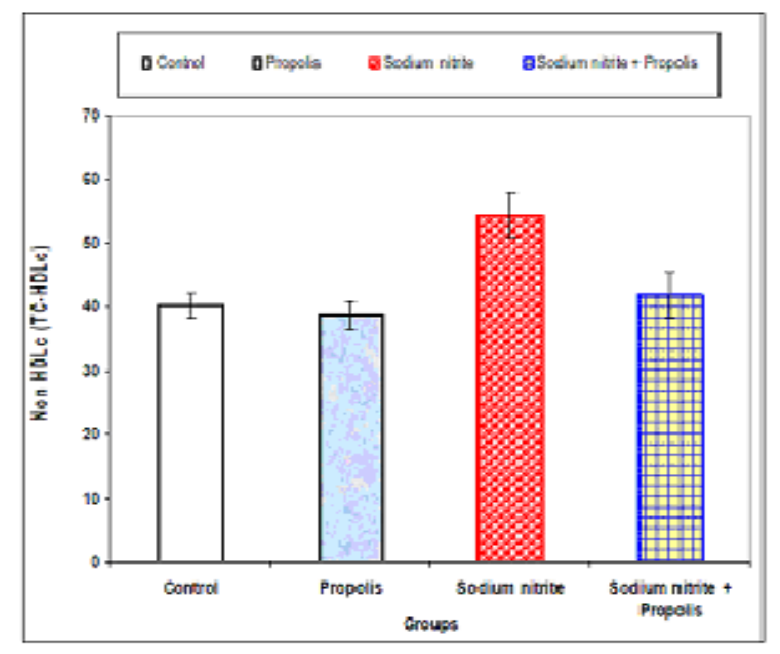

Figure 14. Serum non HDL-cholesterol( $T C-H D L c)$ concentration in different animals groups. 


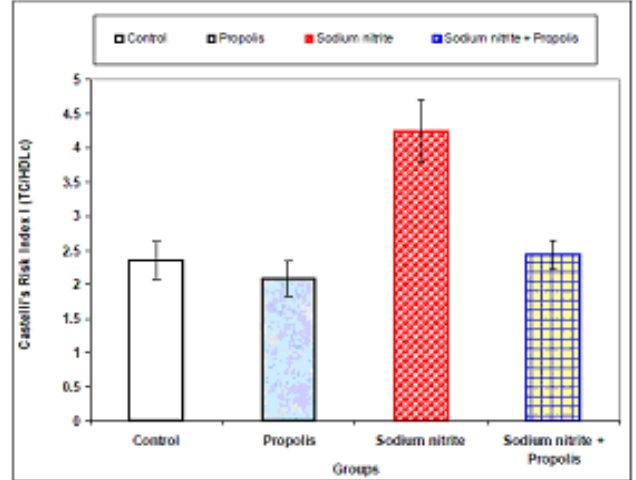

Figure 15. Cardiac Risk Ratio (Castelli's Risk Index I) in different animals groups.

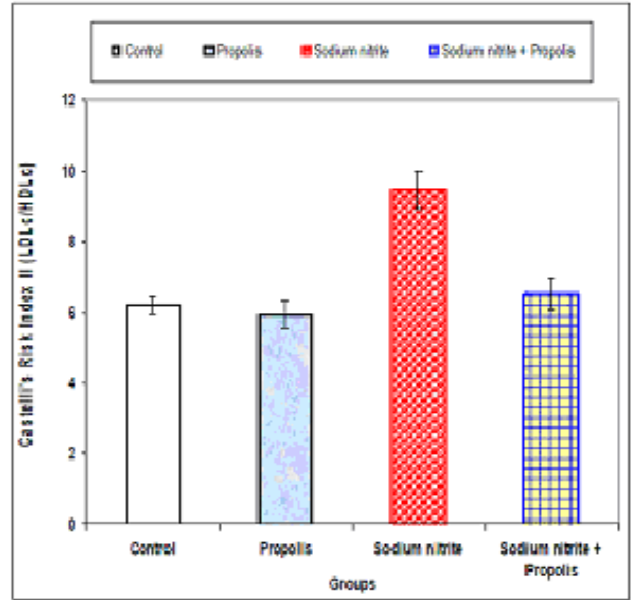

Figure 16. Castelli's Risk Index II in different animals groups

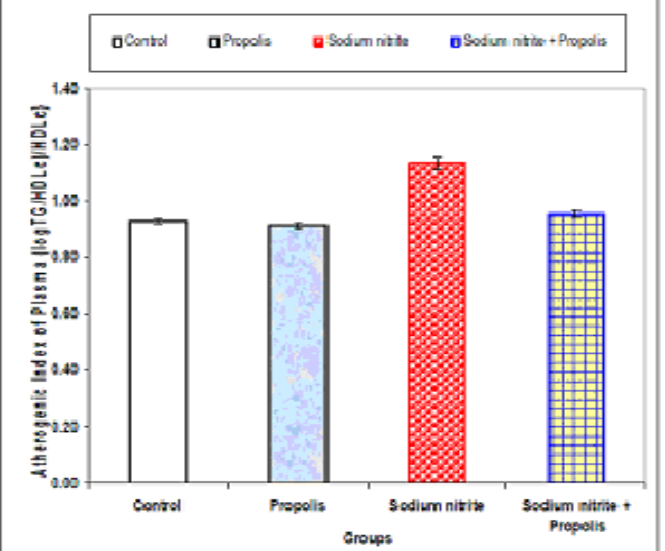

Figure 17. Atherogenic Index of Plasma(AIP) in different animals groups.

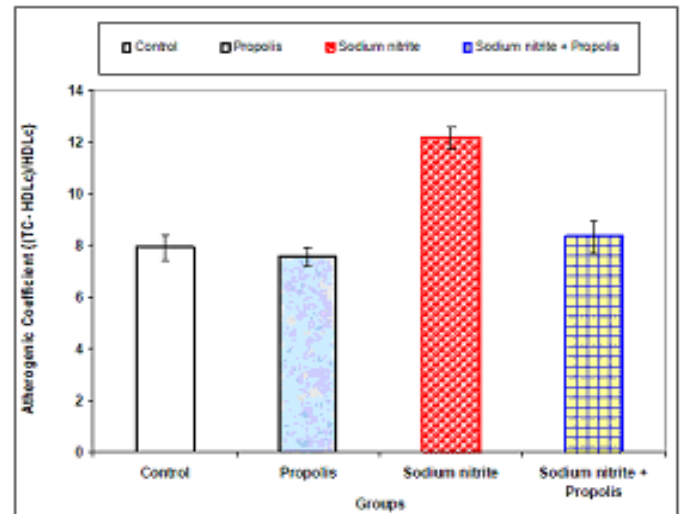

Figure 18. Atherogenic Coefficient in different animals groups.

Table 1. Effect of aqueous extract of propolis on the haematological parameters in different Guinea pigs groups.

\begin{tabular}{lllll}
\hline \multirow{3}{*}{ Parameters } & \multicolumn{3}{c}{ Groups } \\
\cline { 2 - 5 } & Control & Propolis & Sodium nitrite & Sodium nitrite + Propolis \\
\cline { 2 - 5 } & Mean + SD & Mean + SD & Mean + SD & Mean + SD \\
\hline Red blood cell count $\left(\mathrm{x} 10^{6 /} / \mu \mathrm{l}\right)$ & $5.19 \pm 0.26$ & $5.51 \pm 0.22$ & $3.63 \pm 0.37^{\mathrm{a}}$ & $4.92 \pm 0.42^{\mathrm{b}}$ \\
Hemoglobin content $(\mathrm{g} / \mathrm{dl})$ & $13.98 \pm 0.51$ & $14.14 \pm 0.49$ & $9.09 \pm 0.83^{\mathrm{a}}$ & $13.56 \pm 0.75^{\mathrm{b}}$ \\
Haematocrit $(\%)$ & $39.50 \pm 0.98$ & $40.80 \pm 0.76$ & $28.80 \pm 0.91_{\mathrm{a}}$ & $38.60 \pm 1.13^{\mathrm{b}}$ \\
Mean corpuscular volume $\left(\mu^{3}\right)$ & $76.10 \pm 0.88$ & $74.00 \pm 0.97$ & $79.40 \pm 0.93^{\mathrm{a}}$ & $78.10 \pm 0.51^{\mathrm{b}}$ \\
Mean corpuscular hemoglobin $(\mathrm{pg})$ & $26.90 \pm 0.45$ & $25.70 \pm 0.43$ & $25.00 \pm 0.59^{\mathrm{a}}$ & $27.60 \pm 0.51^{\mathrm{b}}$ \\
Mean corpuscular hemoglobin concentration $(\mathrm{g} / \mathrm{dl})$ & $35.40 \pm 0.83$ & $34.70 \pm 0.89$ & $31.50 \pm 0.91^{\mathrm{a}}$ & $35.30 \pm 0.79^{\mathrm{b}}$ \\
White blood cell count $\left(\mathrm{x} 10^{\mathrm{b}} / \mu \mathrm{l}\right)$ & $7.45 \pm 0.54$ & $7.69 \pm 0.62$ & $5.97 \pm 0.46^{\mathrm{a}}$ & $7.22 \pm 0.42^{\mathrm{b}}$ \\
Platelets count $\left(\mathrm{X} 10^{3} / \mu \mathrm{L}\right)$ & $430 \pm 14.4$ & $446 \pm 18.3$ & $402 \pm 10.8^{\mathrm{a}}$ & $451 \pm 13.7^{\mathrm{b}}$ \\
\hline
\end{tabular}

a: Significant differences as compared with control group $(\mathrm{P}<0.05)$. b: Significant differences as compared with sodium nitrite treated group $(\mathrm{P}<0.05)$. All data are mean of 6 individuals.

Table 2. Effect of aqueous extract of propolis on serum lipid profile parameters in different Guinea pigs groups.

\begin{tabular}{|c|c|c|c|c|}
\hline \multirow{3}{*}{ Parameters } & \multicolumn{4}{|c|}{ Groups } \\
\hline & Control & Propolis & Sodium nitrite & Sodium nitrite + Propolis \\
\hline & Mean + SD & Mean + SD & Mean + SD & Mean + SD \\
\hline Cholesterol concentration $(\mathrm{mg} / \mathrm{dl})$ & $45.30 \pm 2.21$ & $43.80 \pm 3.86$ & $58.90 \pm 4.1^{\mathrm{a}}$ & $46.82 \pm 2.51^{\mathrm{b}}$ \\
\hline Triglycerides concentration $(\mathrm{mg} / \mathrm{dl}$ ) & $43.26 \pm 2.2$ & $41.78 \pm 2.38$ & $60.56 \pm 4.13^{\mathrm{a}}$ & $45.32 \pm 3.36^{\mathrm{b}}$ \\
\hline High density lipids cholesterol concentration ( $\mathrm{mg} / \mathrm{dl}$ ) & $5.08 \pm 0.28$ & $5.11 \pm 0.21$ & $4.47 \pm 0.17^{\mathrm{a}}$ & $5.01 \pm 0.15^{\mathrm{b}}$ \\
\hline Low density lipids cholesterol concentration (mg/dl) & $31.57 \pm 2.01$ & $30.33 \pm 2.32$ & $42.32 \pm 3.10^{\mathrm{a}}$ & $32.75 \pm 2.18^{\mathrm{b}}$ \\
\hline Very low density lipids cholesterol concentration $(\mathrm{mg} / \mathrm{dl})$ & $8.65 \pm 0.73$ & $8.36 \pm 0.62$ & $12.11 \pm 0.81^{\mathrm{a}}$ & $9.06 \pm 0.87^{b}$ \\
\hline Non $H D L c(T C-H D L c)(m g / d l)$ & $40.22 \pm 2.1$ & $38.69 \pm 2.2$ & $54.43 \pm 3.5^{\mathrm{a}}$ & $41.81 \pm 3.7^{\mathrm{b}}$ \\
\hline
\end{tabular}

a: Significant differences as compared with control group $(\mathrm{P}<0.05)$. b: Significant differences as compared with sodium nitrite treated group $(\mathrm{P}<0.05)$. All data are mean of 6 individuals. 
Table 3. Effect of aqueous extract of propolis on the ratios based on lipid profile parameters of in different Guinea pigs groups.

\begin{tabular}{lllll}
\hline \multirow{2}{*}{ Parameters } & \multicolumn{3}{c}{ Groups } \\
\cline { 2 - 5 } & Control & Propolis & Sodium nitrite & Sodium nitrite + Propolis \\
\cline { 2 - 5 } & Mean + SD & Mean + SD & Mean + SD & Mean + SD \\
\hline Cardiac Risk Ratio (Castelli's risk index I) TC/HDLC & $2.35 \pm 0.28$ & $2.08 \pm 0.26$ & $4.25 \pm 0.45^{\mathrm{a}}$ & $2.43 \pm 0.21^{\mathrm{b}}$ \\
Castelli's risk index II (LDLc/HDLc) & $6.21 \pm 0.25$ & $5.94 \pm 0.38$ & $9.47 \pm 0.54^{\mathrm{a}}$ & $6.54 \pm 0.43^{\mathrm{b}}$ \\
Atherogenic index of plasma(AIP) log(TG/HDLC) & $0.93 \pm 0.031$ & $0.91 \pm 0.028$ & $1.13 \pm 0.041^{\mathrm{a}}$ & $0.96 \pm 0.023^{\mathrm{b}}$ \\
Atherogenic coefficient (TC- HDLc)/HDLc\} & $7.92 \pm 0.5$ & $7.57 \pm 0.37$ & $12.18 \pm 0.41^{\mathrm{a}}$ & $8.35 \pm 0.62^{\mathrm{b}}$ \\
\hline
\end{tabular}

a: Significant differences as compared with control group $(\mathrm{P}<0.05)$. b: Significant differences as compared with sodium nitrite treated group $(\mathrm{P}<0.05)$. All data are mean of 6 individuals.

\section{Discussion}

The present study showed that treatment of male Guinea pigs with sodium nitrite were decreased red blood cell count, hemoglobin concentration, haematocrite, mean corpuscular hemoglobin, mean corpuscular hemoglobin concentration and a significant increased mean corpuscular volume values as compared to the control Guinea pigs. Similar observations in erythrogram values were reported by $\mathrm{Abu}$ Aita and Mohammed [5] who found that a significant decreases in RBCs count, $\mathrm{Hb}, \mathrm{Ht}, \mathrm{MCHC}$, and increase MCV values in rats treated with $30 \mathrm{mg} / \mathrm{kg}$ body weight sodium nitrite for 2 months. Helal [6] reported that administration of both sodium nitrite and sunset yellow for one month to rats induced a decrease of WBCs count, RBCs count, haemoglobin content and haematocrite. It is known that nitrites convert the ferrous ion of haemoglobin to ferric ion both in vivo and vitro [27]. This can explain the reduction of haemoglobin level. In other words, administration of both nitrite and sunset yellow leads to haematopoietic tissue hypoxia resulting on the long term (one month) to a decrease of red blood cell production and hence to reduction of blood haemoglobin level [6].

Also, Ibrahim et al., [28] reported that a significant decrease in $\mathrm{Hb}$ of rats taken high dose of sodium nitrite at ten weeks of experiment. The developed anaemia may be referred to the toxic effect of sodium nitrite on bone marrow, spleen and liver $[5,29]$. Oxidative damage might be a more relevant cause of decreasing $\mathrm{RBC}, \mathrm{Hb}$, Hct which may be attributed to methaemoglobinaemia [28, 30] resulted from direct reaction of sodium nitrite on $\mathrm{Hb}$ which led to cell destruction [28, 31]. These changes may be attributed to haemolysis that resulted from MetHb formation. Furthermore, peroxynitrite ONOO-, a cytotoxic species (formed in vivo via the reaction between nitrite met $\mathrm{Hb}$ and hydrogen peroxide) and hypoxia (produced as result of methaemoglobinaemia) incriminated in high rate of hemolysis [28, 32]. Oxidative damage to haemoglobin resulting in Heinz body formation and/or methemoglobinaemia is a widely used indicator of oxidant damage in $\mathrm{RBC}[33,34]$ resulting in important functional alterations, and both membrane and cytoplasmic structures are affected by such an oxidant attack [35]. Distorted RBC with increasing nitrite concentration leads to hypoxia since these are the component of blood for oxygen uptake and delivery [36].

The present study showed that administration of sodium nitrite to Guinea pigs had significantly lower WBCs counts, and platelets count compared to control group. These findings are similar to Abu Aita and Mohammed [5] who recorded that a significant decrease in the total leukocytic count of sodium nitrite administered rats in comparable to control group. The recorded leukopenia was associated with lymphopenia which reflects the immunosuppressive effect of sodium nitrite [5,37]. Rats administrated sodium nitrite in drinking water for 14 weeks showed a significant decrease in blood platelets compared with controls [38].

The present data indicated that cholesterol, triglycerides, LDLc and VLDL concentrations were significantly increased by sodium nitrite treatment, while HDL-c concentration was decreased in the serum. Several studies have shown that sodium nitrite exposure induces alterations in serum lipid profiles $[1,7]$. These results run parallel to those reported by Sherif, and Al-Gayyar,[1] who found that treatment of rats with sodium nitrite at a dose of $80 \mathrm{mg} / \mathrm{kg}$ body weight daily for 12 weeks were increased serum cholesterol, triglycerides, LDL and VLDL concentrations compared with control rats. Abu Aita and Mohammed [5] reported that significant hypercholesterolemia was recorded in sodium nitrite administered rats compared to control group. This elevation may be due to the mobilization of free fatty acids from the adipose tissue to the blood stream and increase level of acetyl CoA, leading to increase in the synthesis of cholesterol or due to peroxidation of cell membrane lipids [5, 39]. Lowering levels of high density lipoprotein was a contrary effect because high HDL levels have been shown to bear an inverse correlation with risks for atherosclerosis [40]. Cholesterol is an essential part of every cell in the body. It is necessary for formation of new cells and for older cells to repair themselves after injury. It is also used by the adrenal glands in the synthesis of some hormone, such as cortisol, by the testicles to form testosterone, and by the ovaries to form estrogen and progesterone [41]. The high cholesterol level in plasma may be due to increased uptake of exogenous cholesterol and subsequent deposition and decreased cholesterol catabolism as evidenced by a reduction in bile acid production and turnover of bile acids. The metabolism of free and ester cholesterol are impaired in liver, spleen and thymus tissue and the rate of turnover was specifically decreased in all tissues of hyperlipidemic rats [42]. Increase in LDL, VLDL levels are increase the risk of cardiovascular diseases [43, 44]. Oxidative stress, specifically the oxidation of low density lipoprotein, has long been suspected of having a critical role in the development of atherosclerosis, in consequence of which antioxidants have been expected to have potential as 
antiatherogenic agents. Such agents would be able to inhibit the oxidative modification of LDL that leads to the accumulation of cholesterol in atherosclerotic lesions $[45,46]$.

Results of the present study have shown that Castelli's risk index I, Castelli's risk index II, atherogenic coefficient and atherogenic index of plasma were elevated in sodium nitrite treated Guinea pigs group compared with the control group with statistically significant differences $(p<0.05)$. These findings are similar to Azab et al., [16] who recorded that elevations in Castelli's risk index I, Castelli's risk index II, atherogenic coefficient and atherogenic index of plasma in mice treated with lead acetate. Bhardwaj et al. [47] reported that lipid ratios like atherogenic Index of plasma, Castelli risk index and atherogenic coefficient could be used for identifying individuals at higher risk of cardiovascular disease in Indian population in the clinical setting especially when the absolute values of individual lipoproteins seem normal and in individuals with elevated triglycerides concentrations. Thus, the use of these indexes should be encouraged to complement the existing profile of tests for identifying high risk individuals for coronary artery disease and effective drug management.

The present study showed that administration of propolis alone to Guinea pigs did not cause any significant alteration in the haematological indices. These findings are similar to the data reported by Jasprica et al. [48] who recorded that administration of propolis did not cause any significant changes in haematological parameters such as blood cells, hemoglobin concentration and haematocrit in humans.

In our study, administration of propolis alone to Guinea pigs did not cause any significant alteration on the serum cholesterol, triglycerides, HDL-c, LDL-c, and VLDL-c levels. These results agreed with that observed by Azab et al., [16] who reported that administration of propolis alone did not cause any significant alteration on the serum cholesterol, triglycerides, HDL-c, LDL-c, and VLDL levels. These findings are similar to the data reported by Sforcin et al. [49], Mani et al. [50], and Gomaa et al., [51] who demonstrated that treatment with propolis did not cause any significant change in biochemical parameters such as triglyceride and total cholesterol in rats.

Co-administration of sodium nitrite with propolis were significantly prevented the changes recorded in erythrogram values which caused by treatment of Guinea pigs with sodium nitrite only as compared with control group. Similar results were recorded in rats concurrently administered sodium nitrite with marjoram oils. Marjoram oil contains essential oils that inhibit lipid peroxidation in the membranes of erythrocytes that resulted in increasing membrane resistance to spontaneous hemolysis, decreasing membrane microviscosity, maintenance of their integrity and functional activity [52]. Our results are in accordance with the findings that treatment of rats with propetamphos plus propolis increased total leukocyte count compared to rats treated with propetamphos [14]. The increase observed in total leukocyte count may indicate an activation of the animal's immune system. Previous studies have shown that propolis has anti-inflammatory and immunomodulatory activities [53, 54]. It has been also reported that propolis treatment increased proliferation of leucocyte precursors from pluripotent stem cell in mice [55].

Results of the present study which have shown that co-administration of propolis with sodium nitrite to male Guinea pigs induced significant reduction in serum cholesterol, triglycerides, LDL-c and VLDL-c concentrations and elevation in serum HDL- cholesterol. These results are in concordant with those of Azab et al., [16] who reported that co-administration of propolis with lead acetate induced significant reduction in serum cholesterol, triglycerides, LDLc and VLDL concentrations and elevation in serum HDLcholesterol. Also, El-Nahrawy et al.,[56] reported that monosodium glutamate administration to male albino rats exerted significant elevation of the serum cholesterol, triglycerides, LDL, and VLDL levels. The protective group was first administered propolis alone for 4 weeks, and secondly received Monosodium glutamate in association with propolis for 4 weeks. In the protective group, propolis extract showed significant improvement in the previous fractions. Decrease in triglyceride and cholesterol levels following propolis intake may be related to the influence of propolis itself on lipid metabolism [56]. Antioxidants and flavonoids can act as inhibitors of lipid peroxidation by scavenging polyunsaturated fatty acids peroxy radicals and interrupting the chain reactions [57]. It is well-known that phenolic antioxidants can trap initiating radicals and/or propagating peroxy radicals to break the peroxidation chain reaction to protect the cells from oxidation damage [58]. Co-administration of propolis to chlorpyrifos treated rats restored serum total cholesterol, triglycerides and LDL-cholesterol parameters to normal levels [51]. Also, Cetin et al., [14] found that treatment of rats with propetamphos plus propolis decreased triglyceride levels compared to the rats treated with propetamphos. This suggests that propolis can modulate lipid metabolism. Fuliang et al., [59] reported propolis to cause decrease in triglyceride level when administered to rats with diabetes mellitus. In addition, Kolankaya et al., [60] reported that propolis caused a decrease in triglyceride level of rats treated with alcohol. Oral ethanolic extracts of propolis (EEP) caused a significant decrease in plasma levels of total cholesterol, triacylglycerol, LDL-cholesterol and VLDL-cholesterol and significant increase in HDL-cholesterol in rabbits fed cholesterol diet. The data suggest that EEP may be protective against atherosclerosis and cardiovascular disease, particularly because they also decreased plasma LDL-cholesterol level [61]. Flavonoids supplementation significantly increased HDL-cholesterol and HDL-cholesterol/ total-cholesterol ratio [62]. The favorable lipid profile indicates a possible antiatherogenic property of the flavonoids [63]. Bok et al.,[64] suggest that flavonoids reduce cholesterol biosynthesis by means of inhibition of hepatic 3-hydroxy-3-methylglutaryl-CoA (HMG-CoA) reductase and acyl CoA: cholesterol o-acyltransferase (ACAT). Reduced ACAT activity may lead to lower availability of cholesterol ester for 
VLDL cholesterol packing, thereby resulting in a reduction of VLDL cholesterol secretion from the liver, as suggested by Carr et al., [65]. Diets containing flavonoids reduced the VLDL [66].

Increases of HDL have cardio-protective effect and it was proved by various studies. [43, 44]. The increase in HDL-C observed in the present study, might be due to stimulation of pre- $\beta$ HDL-C and reverse cholesterol transport as demonstrated by previous studies [42, 67]. High HDL-C levels could potential contribute to its anti-atherogenic properties, including its capacity to inhibit LDL oxidation and protect endothelial cells from the cytotoxic effects of oxidized LDL [68]. The ethanol extract of propolis resulted in decreased serum levels of total cholesterol, triacylglycerol, LDL-cholesterol, VLDL-cholesterol of fasting rats; and to increased serum levels of HDL-cholesterol. This suggests that propolis can modulate the metabolism of blood lipid [59].

In the present study, co-administration of sodium nitrite with propolis were reduced Castelli's risk index I, Castelli's risk index II, atherogenic coefficient and atherogenic index of plasma with statistically significant differences $(p<0.05)$, when compared with sodium nitrite treated group. This is in agreement with Azab et al.,[16] who recorded that a decreases in Castelli's risk index I, Castelli's risk index II, atherogenic coefficient and atherogenic index of plasma with statistically significant differences $(p<0.05)$ in mice co-administrated of lead acetate with propolis, when compared with lead acetate treated group.

In our study hypolipidemic and antiatherogenic effects of aqueous extract of propolis may be due to the antioxidant actions of the extract. Some antioxidant compounds identified in propolis include ferulic acid, quercetin and caffeic acid [69]. Some propolis is made bioactive by the presence of prenylated compounds [70]. Russo et al., [71] studied a propolis and determined the antioxidant properties that are conferred by galangin, caffeic acid, ferulic acid, pcumaric and CAPE. The antioxidant activities of propolis are related to its ability to scavenge singlet oxygen, superoxide anions, proxy radicals, hydroxyl radicals and peroxynitrite [72]. The primary mechanism of the effect of propolis may involve the scavenging of free radicals that cause lipid peroxidation. The other mechanism may comprise the inhibition of xanthine oxidase, which is known to cause free radicals to be generated [73].

\section{Conclusion}

The present study, concluded that, sodium nitrite had adverse effects on some haematological parameters, lipids profile, and atherogenic ratios in the blood serum. Propolis supplementation showed a remarkable amelioration of these abnormalities in sodium nitrite treated male Guinea pigs. It is recommended that the use of sodium nitrite must be limited and use of propolis as antioxidant to prevent the toxic effect. Further studies are necessary to elucidate exact mechanism of protection of haematotoxicity, hyperlipidemia, atherogenic and potential usefulness of aqueous extract of Libyan propolis as a protective agent against sodium nitrite induced haematotoxicity, dyslipidemia and atherogenic in clinical trials.

\section{References}

[1] Sherif IO, and Al-Gayyar MMH: Antioxidant, anti-inflammatory and hepatoprotective effects of silymarin on hepatic dysfunction induced by sodium nitrite. Eur. Cytokine Netw. 2013; 24(3): 114-121.

[2] Binkerd EF, and Kolari OE: The history and use of nitrate and nitrite in the curing of meat. Food Cosmet Toxicol 1975; 13: 655-661.

[3] Abdeen AM, EL-Shayeb AF, Hassan HA and. El-Agamy SA: The protective role of garlic oil against the histopathological and histochemical changes induced by sodium nitrite toxicity in kidneys of albino rats. J Jazan Univ Appl Sci Branch 2015; (4): 57-67.

[4] De Saint Blanquat G, Fritsch P, and Cazottes C: Effects of dietary nitrite and nitrate on experimentally-induced inflammation in the rat. Int J Tissue React 1983; 5: 173-180.

[5] Abu Aita NA and Mohammed FF: Effect of marjoram oil on the clinicopathological, cytogenetic and histopathological alterations induced by sodium nitrite toxicity in rats. Glob Veter 2014; 12 (5): 606-616.

[6] Helal EGE: Progressive effects of the interaction of Sodium nitrite and sunset yellow on different physiological parameters in albino rats. Egypt J Hosp Med 2001;2 : 23 - 46.

[7] Enovwo, O: Effects of aqueous extracts of ginger (Zingiber officinale) and onions (Allium cepa) on some biochemical parameters in plasma following oral intake of sodium nitrite by Wistar albino rats. M. Sc. Thesis, Med Biochem, Port Harcourt Univ 2010.

[8] Al-Mamary M, Al-Meeri A, Al-Habori M: Antioxidant activities and total phenolics of different types of honey. Nutr Res 2002; 22: 1041-1047.

[9] Marquele FD, Di Mambro VM, Georgetti SR, Casagrande R, Valim YML and Fonseca MJV: Assessment of the antioxidant activities of Brazilian extracts of propolis alone and in topical pharmaceutical formulation. J Pharmacol Biomed Anal 2005; 39: 455-462.

[10] Fokt H, Pereira A, Ferreira AM, Cunha A, and Aguiar C: How do bees prevent hive infections? The antimicrobial properties of propolis. Current research, technology and education topics in applied microbiology and microbial biotechnology. Mendez A (Ed.) 2010.pp. 481-493.

[11] Papotti G, Bertelli D, Bortolotti L, and Plessi M: Chemical and functional characterization of Italian propolis obtained by different harvesting methods. J Agri Food Chem 2012; 60:2852-2862.

[12] Ahn M, Kumazawa S, Hamasaka T, Bang K, and Nakayama T: Antioxidant activity and constituents of propolis collected in various areas of Korea. J Agr Food Chem 2004; 52:7286-7292.

[13] Orsolic N, Knezevic AH, Sver L, Terzic S, and Basic I: Immuno-modulatory and antimetastatic action of Propolis and related polyphenolic compounds. J Ethnopharm 2004; 94: $307-$ 315 . 
[14] Cetin E, Kanbur M, Silici S and Eraslan G: Propetamphos induced changes in haematological and biochemical parameters of female rats: Protective role of propolis. Food Chem Toxicol 2010; 48: 1806 -1810.

[15] Seo KW, Park M, Song Y.J, Kim S, and Yoon KR. The protective effects of propolis on hepatic injury and its mechanism. Phyto Res 2003; 17:250-253.

[16] Azab AE, Algridi MA and Lashkham NM: Hypolipidemic and antiatherogenic effects of aqueous extract of Libyan propolis in lead acetate intoxicated male albino mice. IJSR 2015; 4(3): 1060-1068.

[17] Abd El-Rahman SS: West-Libyan propolis and rosemary have synergistic anti-tumor effect against 12-O-tetradecanoylphorbol 13-acetate-induced skin tumor in BULB/C mice previously initiated with 7,12-dimethy lbenz[a]anthracene. Basic Appl Pathol 2010; 3: 46 -51.

[18] Hassan HA, El-Agmy SM, Gaur RL, Fernando A, Raj MHG, and Ouhtit A: In vivo evidence of hepato- and reno-protective effect of garlic oil against sodium nitrite-induced oxidative stress. Inter J Biol Sci 2009; 5(3):249-255.

[19] El-Khayat Z, Ezzat AR, Arbid MS, Rasheed WI, and Elias TR: Potential effects of bee honey and propolis against the toxicity of ochratoxin a in rats. Macedonian J Med Scie 2009; 2(4): 1-8.

[20] Ashry MA, Abd Ellah HF and Gheth EMM: The possible ameliorative effect of propolis in rat's liver treated with monosodium glutamate. Nature Sci 2012; 10(12): 209 - 219.

[21] Wong SY: Colorimetric determination of iron and hemoglobin in blood. J Bio Chem 1982; 77: 409.

[22] Schalm, OW: Veterinary haematology, fourth ed. Lea and Febiger, Philadelphia. 1986, p. 21-86.

[23] Allain CC, Poon LS, Chan CSG, Richmond W and Fu PC: Enzymatic determination of total serum cholesterol. Clin Chem 1974; 20(4): 470-475.

[24] Fossoti, P and Prencipe L: Serum triglycerides determination calorimetrically with an enzyme that produces hydrogen peroxide. Clin Chem 1982; 28(10):2077-2080.

[25] Burstein M, Scholnik H and Morfin R: Rapid method for the isolation of lipoproteins from human serum by precipitation with polyphenols. J lipid Res 1970; 11: 583-595.

[26] Friedwald W, Levy R and Fredrichson D: Estimation of the concentration of low density lipoprotein cholesterol in plasma without use of the preparative ultracentrifuge. Clin Chem 1972; 226: 499-502.

[27] Ganong, WF: Review of Medical Physilogy. 8th ed. Libraure du liban, Appelton of Longe, lebanon, California 1997:296 311 .

[28] Ibrahim IA, Hassan AGA, Shalaby AA, Dessouki AA and Habib DS: Biochemical studies on the effect of sodium nitrite and butylated hydroxytoluene in rats. SCVMJ 2009; 14 (2): 265-278.

[29] Abu-El-Zahab, HS, El-Khyat ZA and Sidhom G: Physiological effects of some synthetic food coloring additives on rats. Boll Chem Farm 1997; 136(10): 615-627.

[30] Rahman, MM, Kim SJ, Kim GB, Hong CU, Lee YU, Kim SZ, Kim JS and Kang HS: Nitrite induced methemoglobinaemia affects blood ionized and total magnesium level by hydrolysis of plasma adenosine triphosphate in rat. Basic Clin. Pharmacol. Toxicol. 2009; 105: 294-300.

[31] Starodubt Seva MN, Igna-tenko VA and Cherenkevich SN: Damage to erythrocytes caused by the interaction of nitrite ions with hemoglobin. Biofizika 1999; 44 (6): 1068-1072.

[32] Wrobel A, Łukaszynska B and Kedzierska J: The effect of peroxynitrite and some antioxidants on the rate of osmotic haemolysis of bovine erythrocytes. Cell Mol Biol Lett 2003; $8(2): 455-460$.

[33] Imaizumi K, Tyuma I, Imai K, Kosaka H, Ueda Y. In vivo studies on methemoglobin formation by sodium nitrite. Int Arch Occup Environ Health 1980; 45: 97-104.

[34] Baskurt OK, Temiz A, and Meiselman HJ: Effect of superoxide anions on red blood cell rheologic properties. Free Radic Biol Med 1998; 24: 102-110.

[35] Baskurt OK, and Yavuzer S: Some haematological effects of oxidants. In: Nriagu JO, Simmons MS (eds). Environmental Oxidants. John Wiley and Sons Inc, New York/Chichester/ Brisbane/Toronto/Singapore, 1994: 405-423.

[36] Park JH, Phothimat P, Oates CT, Hernanz-Schulman M, and Olsen NJ: Use of P-31 magnetic resonance spectroscopy to detect metabolic abnormalities in muscles of patients with fibromyalgia. Arthritis Rheum 1998; 41: 406 - 413.

[37] Gluhcheva Y, Ivanovb I, Petrovaa E, Pavlovaa E and Vladov I: Sodium nitrite induced haematological and haemorheological changes in rats. Series Biomechan 2012; 27(3-4): 53-58.

[38] Chan PC, Bristol DW, Bucher JR, Chapin RE, Hailey JR, Haseman JK, Maronpot RR, Orzech DP, Rao GN, Roycroft $\mathrm{JH}$, et al.,: Technical report on the toxicology and carcinogenesis studies of sodium nitrite (NTP TR 495). National toxicology program, NIH publication no. 01-3954 U.S. department of health and human services, public health service national institutes of health.2001.

[39] Helal, EGE, Zahkouk SA and Mekawy HA: Effect of some food colours (synthetic and natural products) on liver and kidney functions of young albino rats. Egypt. J. Hosp. Med. 2000; 1: 103-113.

[40] Miller NE: Associations of high-density lipoproteinsubclasses and apolipoproteins with ischemic heart disease and coronary atherosclerosis. Am Heart J 1987; 113: 589-597.

[41] Jefcoate C R, McNamara BC, Artemenko I and Yamazaki T: Regulation of cholesterol movement to mitochondrial cytochrome P450scc in steroid hormone synthesis. J Steroid Biochem Mol Biol. 1992; 43(8):751- 767.

[42] Barakat LAA and Mahmoud RH: The antiatherogenic, renal protective and immunomodulatory effects of purslane, pumpkin and flax seeds on hypercholesterolemic rats. North Amer J Med Sci 2011; 3(9): 351 - 357.

[43] Roy S: Antioxidant and protective effect of latex of Calotropis procera against alloxan induced diabetes in rats. J Ethnopharmacol. 2005; 102(3): 470-473.

[44] Jaiswal J, Bhardwaj H, Srivastava S, Gautam H, Sharma S and Rao C: Anti-diabetic activity of methanolic extract of Calotropis gigantea seeds on STZ induced diabetic rats. Int J Pharm Pharm Sci. 2013; 6(1): 254-257. 
[45] Brown MS and Goldstein JL: Lipoprotein metabolism in the macrophage: implications for cholesterol deposition in atherosclerosis. Annu. Rev. Biochem. 1983; 52:223-261.

[46] Suzuki H, Kurihara Y, Takeya M, Kamada N, Kataoka M, Jishage K, Ueda O, Sakaguchi H, Higashi T, Suzuki T, et al: A role for macrophage scavenger receptors in atherosclerosis and susceptibility to infection. Nature 1997; 386(6622): 292-296.

[47] Bhardwaj S, Bhattacharjee J, Bhatnagar MK and Tyagi S: Atherogenic index of plasma, castelli risk index and atherogenic coefficient- new parameters in assessing cardiovascular risk. Int J Pharm Bio Sci 2013; 3(3):359-364.

[48] Jasprica I, Mornar A, Debeljak Z, Bubalo AS, Saric MM, Mayer L, Romic, Bucan Z, Bagol K, Sobocanec T, Sverko SV: In vivo study of propolis supplementation effects on antioxidative status and red blood cells. J. Ethnopharmacol. 2007; 110: 548-554.

[49] Sforcin JM, Funari SRC, Novelli ELB: Serum biochemical determinationsof propolis treated rats. J Venom Anim Toxins 1995; 1: 31-37.

[50] Mani F, Damasceno HCR, Novelli ELB, Martins EAM, and Sforcin JM: Propolis: effect of different concentrations, extracts and intake period on seric biochemical variables. J. Ethnopharmacol 2006; 105: 95-98.

[51] Gomaa MS, Abd Alla MA and Sameer MM: The possible protective effect of propolis (bee glue) on cypermethrin-induced hepatotoxicity in adult albino rats. Mansoura J. Forensic Med. Clin. Toxicol 2011; 21(1):17 - 32.

[52] Kasperczyk S, Birkner E, Kasperczyk A and Kasperczyk J: Lipids, lipid peroxidation and 7-ketocholesterol in workers exposed to lead. Hum Exp Toxicol 2005; 24: 287- 295.

[53] De Castro SL: Propolis: biological and pharmacological activities. Therapeutic uses of this bee-product. Annu Rev Biomed Sci 2001; 3: 49-83.

[54] Dantas AP, Olivieri BP, Gomes FHM, and De Castro SL: Treatment of Trypanosoma cruzi infected mice with propolis promotes changes in the immune response. J Ethnopharmacol 2006; 103: 187-193.

[55] Orsolic N, and Basic I: Antitumor, haematostimulative and radioprotective action of water soluble derivative of propolis. Biomed Pharmacother 2005; 59: 561-570.

[56] El-Nahrawy WAM, Wahba SMR and Eldurssi IS: The potential effects of propolis against monosodium glutamate toxic effects on some biochemical aspects of kidney. Life Sci J 2012; 9(4): 4044- 4054.

[57] Pascual C, Gonzalez R and Torricella, R: Scavenging action of propolis extract against oxygen radicals. $\mathrm{J}$ Ethnopharmacol 1994; 41: 9-13.

[58] Maiti K, Mukherjee K, Gantait A, Ahamed HN and Saha BP: Enhanced therapeutic benefit of quercetin- phospholipid complex in carbon tetrachloride induced acute liver injury in rats: a comparative study. Iranian J. Pharmacol. Ther 2005; 4: 84-90.

[59] Fuliang HU, Hepburn HR, Xuan H, Che M, Daya S and Radloff SE: Effects of propolis on blood glucose, blood lipid and free radicals in rats with diabetes mellitus. Pharmacol Res 2005; 51: 147-152.

[60] Kolankaya D, Selmanoglu G, Sorkun K and Salih B: Protective effects of Turkish propolis on alcohol induced serum lipid changes and liver injury in male rats. Food Chem 2002; 78: 213-217.

[61] Fernandes AAH, Novelli ELB and Junior A F: Benefical effects of propolis on experimental hypercholesterolaemia in rabbits. J Brazilian Soc Food Nutr 2006; 31(1): 65-78.

[62] Yousef MI, Kamel KI, EsmaiL AM, and Baghdadi HH: Antioxidant activities and lipid lowering effects of isoflavone in male rabbits. Food Chem Toxicol 2005; 42: 1497-1503.

[63] Adaramoye OA, Nwaneri VO, Anyanwu KC, Farombi EO and Emerole GO: Possible antiatherogenic effect of kolaviron (Garcinia kola seed extract) in hyper-cholesterolaemic rats. Clin Exper Pharmacol Physiol 2005; 32(1/2): 40-46.

[64] Bok SH, Lee SH, Park YB, Bae KH, Son KH, Jeong TS and Choi MS: Plasma and hepatic cholesterol and hepatic activities of 3-hydroxy-3-methy-glutaryl-CoA reductase and acyl CoA: Cholesterol transferase are lower in rats fed citrus peel extract or a mixture of citrus bioflavonoids. J Nutr 1999; 129(6): 1182-1185.

[65] Carr TP, Parks JS and Rudel LL: Hepatic ACAT activity in African green monkeys in highly correlated to plasma LDL cholesterol enrichment and coronary artery atherosclerosis. Arteriocler Thromb 1992; 12(11): 1274- 1283.

[66] Kurowska EM and Manthey JA: Hypolipidemic effects and absorption of citrus polymethoxylated flavones in hamsters with diet-induced hypercholesterolemia. J Agr Food Chem 2004; 52(10): 2879-2886.

[67] Daniel M: Medicinal plants: Chemistry and Properties. Science publishers, Enfield, NH, 2006 p. 184.

[68] Assmann G and Nofer J: Anthropometric protective effects of high density lipoproteins. Ann Rev Med 2003; 54: 321-341.

[69] Usami E, Kusano G, Takayose T, Wachi H and Seyama Y: Assessment of antioxidant activity of natural compounds by water and lipid soluble antioxidant factor. Yakugaku Zasshi. 2004; 124: 847-850.

[70] Chen CN, Weng MS, Wu CL and Lin J K: Comparison of radical scavenging activity, cytotoxic effects and apoptosis induction in Human melanoma cells by Taiwanese propolis from different sources. Evid bas Compl Altern Med 2004; 1(2): $175-185$.

[71] Russo A, Troncoso N, Sanchez F, Garbarino J and Vanella A: Propolis protect human spermatozoa from DNA damage caused by benzo [a] pyrene and exogenous reactive oxygen species. Life Sci 2006; 78: 1401-1406.

[72] Ferrali M, Signorini C and Caciotti B: Protection against oxidative damage of erythrocytes membrane by the flavinoid quercetin and its relation to iron chelating activity. FEBS Lett 1997; (416): 123- 129.

[73] Kanbura M, Eraslan G and Silici S: Antioxidant effect of propolis against exposure to propetamphos in rats. Ecotoxicol Environ Safety 2009; (72): 909-915. 